\title{
Investigation of Cytotoxicity, Oxidative Stress, and Inflammatory Responses of Tantalum Nanoparticles in THP-1- Derived Macrophages
}

\author{
Li Zhang $\mathbb{D}^{1}{ }^{1}$ El-Mustapha Haddouti, ${ }^{1}$ Hannes Beckert, ${ }^{2}$ Ralf Biehl, ${ }^{3}$ Shyam Pariyar, ${ }^{4}$ \\ Julian M. Rüwald, ${ }^{1}$ Xian Li, ${ }^{5}$ Max Jaenisch, ${ }^{1}$ Christof Burger, ${ }^{1}$ Dieter C. Wirtz, \\ Koroush Kabir $\oplus^{1},{ }^{1}$ and Frank A. Schildberg $\mathbb{D}^{1}$ \\ ${ }^{1}$ Clinic for Orthopedics and Trauma Surgery, University Hospital Bonn, 53127 Bonn, Germany \\ ${ }^{2}$ Microscopy Core Facility, Medical Faculty, Bonn Technology Campus Life Sciences, University of Bonn, 53127 Bonn, Germany \\ ${ }^{3}$ Jülich Centre for Neutron Science (JCNS-1) \& Institute of Biological Information Processing (IBI-8), Forschungszentrum Jülich, \\ 52425 Jülich, Germany \\ ${ }^{4}$ Department of Horticultural Sciences, University of Bonn, 53121 Bonn, Germany \\ ${ }^{5}$ Department of Orthopedic and Trauma Surgery, Xiyuan Hospital, China Academy of Chinese Medical Science, \\ 100091 Beijing, China
}

Correspondence should be addressed to Koroush Kabir; koroush.kabir@ukbonn.de and Frank A. Schildberg; frank.schildberg@ukbonn.de

Received 31 July 2020; Revised 29 October 2020; Accepted 2 November 2020; Published 3 December 2020

Academic Editor: Marietta Herrmann

Copyright ( 2020 Li Zhang et al. This is an open access article distributed under the Creative Commons Attribution License, which permits unrestricted use, distribution, and reproduction in any medium, provided the original work is properly cited.

\begin{abstract}
Tantalum (Ta) is gaining attention as a biomaterial in bone tissue engineering. Although the clinical advantage of Ta-based implants for primary and revision total joint replacement (TJA) has been well documented, few studies investigated the effect of wear products of Ta implants on peri-implant cells, and their potential contribution to aseptic implant loosening. This study is aimed at examining the cytotoxicity, oxidative stress, and proinflammatory potential of $\mathrm{Ta}$ and $\mathrm{TiO}_{2}$ nanoparticles (NPs) on macrophages in vitro. NPs were characterized using scanning electron microscopy, dynamic light scattering, and energy-dispersive X-ray. To test the NP-mediated cellular response in macrophages, THP-1-derived macrophages were challenged with both NPs, and cytotoxicity was analyzed using CCK-8 and LDH assays. Flow cytometry was used to investigate particle uptake and their internalization routes. NP-mediated oxidative stress was investigated by measuring the production of reactive oxygen species, and their proinflammatory potential was determined by quantifying the production of TNF $\alpha$ and IL- $1 \beta$ in cell culture supernatants using ELISA. We found that both Ta and $\mathrm{TiO}_{2}$ NPs were taken up through actin-dependent phagocytosis, although $\mathrm{TiO}_{2}$ NPs did also show some involvement of macropinocytosis and clathrin-mediated endocytosis. Ta NPs caused no apparent toxicity, while $\mathrm{TiO}_{2} \mathrm{NPs}_{\text {demonstrated significant }}$ cytotoxicity at a concentration of over $100 \mu \mathrm{g} / \mathrm{mL}$ at $24 \mathrm{~h}$. Ta NPs induced negligible ROS generation and proinflammatory cytokines $(\mathrm{TNF} \alpha, \mathrm{IL}-1 \beta)$ in macrophages. In contrast, $\mathrm{TiO}_{2} \mathrm{NPs}$ markedly induced these effects in a dose-dependent manner. Our findings indicate that Ta NPs are inert, nontoxic, and noninflammatory. Therefore, Ta could be considered an excellent biomaterial in primary and revision joint arthroplasty implants.
\end{abstract}

\section{Introduction}

Aseptic loosening is the leading cause of revision surgery and plays a predominant role in limiting the longevity of current total joint arthroplasty (TJA). Wear particles have been recognized as one of the major factors responsible for aseptic implant loosening [1]. After implantation, orthopedic prosthesis becomes an internal source of wear particles [2-5]. Upon corrosion and abrasion, nondegradable biomaterial wear particles are inevitably released in adjacent periimplant tissues or systemically disseminated, inducing local and systemic reactions [6-8]. They represent a long-term 
hazard that interacts with peri-implant cell lineages such as macrophages, fibroblasts, osteoblasts, osteoclasts, and mesenchymal stem cells (MSCs). This process may disrupt local cellular functions; create chronic inflammation, which favors periprosthetic osteolysis; and eventually leads to aseptic implant loosening with subsequent revision surgery. Clinically, as the only established treatment for periprosthetic aseptic loosening, revision TJA is technically demanding and associated with high complication rates, high morbidity, and poor clinical and functional outcomes. Moreover, because of the complexity of the procedure, compromised soft tissue, and bone defects, revision TJA has a greater failure rate than primary TJA [9]. Therefore, choosing the appropriate implant biomaterial is critical for the long-term survival of both primary and revision TJAs.

Tantalum (Ta) is described as an "extremely bioinert" material and has been widely applied as artificial joints, endovascular stents, and coating [10-12]. As biomaterial for implant components in primary and revision TJA, Ta can be formed with a highly porous structure that could mimic the structure of cancellous bone. Similar to titanium (Ti), Ta provides outstanding biocompatibility and corrosion resistance [13, 14]. Moreover, porous Ta components offer lower elastic modulus and higher surface frictional characteristics than conventional Ti implants, thus reducing shielding and improving early stability. These properties make Ta an ideal choice in TJA revision surgery $[15,16]$. Recent studies on failed Ta implant revision hip arthroplasty described nanoscale $\mathrm{Ta}$ fragments (diameters ranging from 9.6 to $243.5 \mathrm{~nm}$ ) released from the implant surface $[17,18]$. Because of this phagocytozable size range and spatial proximity, $\mathrm{Ta}$ nanoparticles (NPs) could be internalized by peri-implant cells, e.g., macrophages, fibroblasts, and MSCs, and provoke hazardous cellular responses. However, the difficulties in purifying and characterizing NPs until today result in an underestimation of the adverse impact of Ta NPs. Therefore, particular attention must be paid to nanoscale Ta wear particles' potentially hazardous effect on peri-implant cells and their potential contribution to repeated prosthetic loosening and subsequent rerevision [19]. However, to date, this topic remains largely unknown.

Macrophages are the critical cells associated with wear particle-induced aseptic loosening. As sentinels of the innate immune system, macrophages are the first immune cells involved in aseptic loosening by recognizing, internalizing, and getting activated upon wear particle exposure [20, 21]. Once activated, macrophages exert an increased proinflammatory phenotype and initiate a chronic inflammatory response characterized by the release of proinflammatory mediators, such as TNF $\alpha$, IL- $1 \beta$, monocyte chemotactic protein-1 (MCP-1), and IL-8 [21, 22]. These reactions create an inflammatory microenvironment that facilitates elevated osteoclastic bone destruction, suppressed bone formation, and ultimately lead to aseptic implant loosening. Therefore, an attempt to elucidate macrophages' response to biomaterial wear debris is critical to understanding the pathology of implant loosening.

The biological response of peri-implant cells to implants is critical for early and late implant success. Recently, emerg- ing in vitro and in vivo studies on osteoblasts and MSCs have demonstrated the Ta-based implants' advantages over commonly used Ti-based implants [23-25]. However, limited research investigated the interaction between Ta implants and other peri-implant cells, such as macrophages. In particular, the biological response of macrophages to Ta implants' wear products, such as nanoscale Ta particles and ions, has never been elucidated. Therefore, this study is aimed at analyzing the effects of Ta NPs on macrophage biology using the THP-1 cell line, an in vitro cell model that is well known, reproducible, and readily available to different labs. To this end, we investigated Ta NPs' uptake routes, cytotoxicity, oxidative stress, and proinflammatory potential on THP-1derived macrophages in vitro.

\section{Materials and Methods}

2.1. Cell Culture and Differentiation. THP-1 cells (American Type Culture Collection, Manassas, VA, USA), a human monocytic leukemia-derived cell line, were cultured in RPMI 1640 medium supplemented with $10 \%$ fetal bovine serum and $1 \%$ penicillin/streptomycin at $37^{\circ} \mathrm{C}$ in a humidified atmosphere with $5 \% \mathrm{CO}_{2}$. For macrophage differentiation, the THP-1 cells were stimulated with $50 \mathrm{ng} / \mathrm{mL}$ phorbol 12 myristate 13-acetate (PMA) (Sigma-Aldrich, Taufkirchen, Germany) overnight.

2.2. Particle Preparation. Ta (NM-0036-HP) and $\mathrm{TiO}_{2}(\mathrm{NO}-$ 0046-HP) nanosized particles were obtained from IoLiTec (Heilbronn, Germany), weighed into autoclaved tubes, and then sterilized by radiation. Stock dispersions $(50 \mathrm{mg} / \mathrm{mL})$ were prepared in phosphate-buffered saline (PBS) solution, followed by $20 \mathrm{~min}$ of continuous sonication using the Emmi-12HC (EMAG AG, Germany) bath sonicator operating at $45 \mathrm{kHz}$ at $30^{\circ} \mathrm{C}$. Then, the stock solution was stored at $4^{\circ} \mathrm{C}$ in the dark. Final dispersions were prepared from a serial dilution of the stock in full cell culture medium followed by another $20 \mathrm{~min}$ sonication at $30^{\circ} \mathrm{C}$ and vigorous vortexing for $5 \mathrm{~s}$ immediately before adding them to the cells.

2.3. Characterization of Particles. The physicochemical properties of particles were analyzed with scanning electron microscopy (SEM) and dynamic light scattering (DLS). The particle morphology and size distribution were determined with SEM. Samples dispersed in $\mathrm{ddH}_{2} \mathrm{O}$ were vortexed before applying $2 \mu \mathrm{L}$ of the mixture onto a silicon wafer. After drying the sample, the wafer was sputtered with an $\sim 2 \mathrm{~nm}$ platinum layer in a Leica ACE600 sputter coater in an argon atmosphere to prepare it for high-resolution field-emission scanning electron microscopy (FESEM) (Crossbeam 550, Zeiss). A Schottky emitter-based field emission Gemini II electron column (Zeiss) was used with $0.8 \mathrm{kV}$ acceleration voltages and currents between $150 \mathrm{pA}$ and $250 \mathrm{pA}$ for imaging. The samples were imaged with the InLens SE (secondary electrons) detector (Zeiss) for topographic imaging (working distance $<3 \mathrm{~mm}$ ). Image (NIH) software was used to determine the size distribution of NPs by randomly selecting 100 particles from the SEM images. The size distribution of NPs was fitted using a Gaussian 
distribution in GraphPad Prism 7 software (GraphPad, La Jolla, CA, USA).

The DLS experiment was carried out with Zetasizer Nano-ZS (Malvern, Worcestershire, Great Britain), which estimates the size distribution from the measured correlation function by nonnegative least square (NNLS) analysis. $\mathrm{TiO}_{2}$ and $\mathrm{Ta}$ NPs were dispersed in $\mathrm{ddH}_{2} \mathrm{O}, \mathrm{PBS}$, RPMI 1640, and RPMI 1640 containing 10\% FBS. Then, samples of NPs were mixed thoroughly via sonication and vortexing before measuring them at $250 \mu \mathrm{g} / \mathrm{mL}$. The scattered light is monitored at an angle of $173^{\circ}$ with a wavelength of $633 \mathrm{~nm}$. Measurements were done at $20^{\circ} \mathrm{C}$ at an average of $10-20$ short frames of $10 \mathrm{~s}$. The observed decay rate is $\Gamma=q^{2} D_{0}$ with scattering vector $q$. The hydrodynamic radius $R_{h}$ is related to the diffusion coefficient $D_{0}$ according to the Stokes-Einstein equation $D_{0}=k_{\mathrm{B}} T / 6 \pi \eta R_{h}$ with the Boltzmann constant $k_{\mathrm{B}}$, temperature $T$ (in $\mathrm{K}$ ), and viscosity $\eta$ of the solvent.

The energy-dispersive X-ray (EDX) analysis was performed using the EDX system (EDAX, Ametek GmbH, Meerbusch, Germany). The EDX system is fitted with a Super Ultrathin Window $\mathrm{Si}$-(Li) detector with a resolution $<138 \mathrm{eV}$ $(\mathrm{MnK} \alpha$ at $1000 \mathrm{cps})$, configured with a take-off angle of $45^{\circ}$ relative to the microscope stage. The Genesis 4000 software (version 3.61) was used to display and evaluate the collected spectra. Measuring adjustments (dwell time $=100 \mu \mathrm{s}$; amplifier integration time $=100 \mu \mathrm{s} ;$ reads $=100$; and map resolution $=512 \times 256$ pixels) remained constant during the measurements. The time required for the analysis of each sample was 655 live seconds. $\mathrm{Al}, \mathrm{Ta}, \mathrm{Si}, \mathrm{Ti}, \mathrm{Fe}, \mathrm{Co}$, and $\mathrm{Ni}$, were chosen for quantification, whereas the other elements such as carbon, oxygen, nitrogen, potassium, and magnesium were not considered (Supplementary Figure 2). Quantification of the elements was standardless using the ZAF-algorithm and selecting the automatic integration of the obtained spectra. The evaluated parameters were the standardized amounts of $\mathrm{Ta}$ and $\mathrm{Ti}$.

2.4. Endotoxin Test. Endotoxin levels in nanoparticle samples were quantified with the Limulus amebocyte lysate (LAL) assay using the ToxinSensor ${ }^{\mathrm{TM}}$ Chromogenic LAL Endotoxin Assay Kit (Genscript) according to the manufacturer's instructions with modifications. This kit has a minimum endotoxin detection limit of $0.01 \mathrm{EU} / \mathrm{mL}$ and a measurable concentration range of 0.01 to $1 \mathrm{EU} / \mathrm{mL} .100 \mu \mathrm{g}$ raw NPs were suspended in $1 \mathrm{~mL}$ endotoxin-free water at $100 \mu \mathrm{g} / \mathrm{mL}$. A volume of $100 \mu \mathrm{L} \mathrm{NP}$ suspension and $100 \mu \mathrm{L}$ of endotoxin standard samples derived from Escherichia coli (0.01-0.1 unit $/ \mathrm{mL}$ ) were incubated with $100 \mu \mathrm{L}$ reconstituted LAL reagent for $30 \mathrm{~min}$ at $37^{\circ} \mathrm{C}$ and a volume of $100 \mu \mathrm{L}$ endotoxin-free water as control. After the initial incubation, $100 \mu \mathrm{L}$ reconstituted chromogenic substrate solution was added into each vial, and the incubation continued for an additional $6 \mathrm{~min}$. The reaction was stopped by adding $500 \mu \mathrm{L}$ of reconstituted color-stabilizer \#1 (stop solution). Then, $500 \mu \mathrm{L}$ of reconstituted color-stabilizer \#2 and \#3 were added. Importantly, particles were removed by two rounds of centrifugation ( $2500 \mathrm{rpm}$ for $15 \mathrm{~min}$ ) as they may interfere with the absorbance value [26]. Finally, the absorbance value of each reaction was determined at $545 \mathrm{~nm}$ using a microplate reader. Distilled water was used as a blank to adjust the photometer to zero absorbance. All samples $(100 \mu \mathrm{L})$ were analyzed in duplicate. Only tests producing a correlation coefficient for the standard curve of 0.98 or greater were accepted. Because NPs may interfere with the endotoxin measurement, all NP samples were measured with and without aliquots of a test sample containing a known amount of the endotoxin $(0.005 \mathrm{EU} / \mathrm{mL})$. The assays were considered reliable if the recovery of spikes was $80-120 \%$.

2.5. Cell Viability Assay. The CCK-8 Cell Counting Kit (Dojindo, Japan) was used to evaluate the viability of macrophages that were treated with $\mathrm{TiO}_{2}$ and Ta NPs. Briefly, THP-1 cells were seeded in 96-well cell culture plates $\left(0.8 \times 10^{5}\right.$ cells/well $)$ with PMA and incubated overnight for differentiation. Cells were then challenged with a series of concentrations of NPs $(20,50,100,200$, and $500 \mu \mathrm{g} / \mathrm{mL}$ and $0.2 \mathrm{~mL} /$ well) for $1 \mathrm{~h}, \mathrm{~h}, 6 \mathrm{~h}, 1 \mathrm{~d}, 3 \mathrm{~d}$, and $7 \mathrm{~d}$. At the end of each time point, the medium was replaced with fresh culture medium containing CCK-8 solution $(1: 10$ in culture medium), and further incubated for another hour at $37^{\circ} \mathrm{C}$ and $5 \% \mathrm{CO}_{2}$. The supernatant was collected and transferred to another 96-well plate to avoid the interference of NPs on optical density (OD) reading. Finally, absorbance was measured at $450 \mathrm{~nm}$ using a microplate reader (Tecan, Männedorf, Switzerland). The viability of the nonchallenged cells was considered $100 \%$.

2.6. Lactate Dehydrogenase Release Assay. Cell culture supernatants from THP-1-derived macrophages were collected after 1, 3, and 7 days after NP exposure. Resulting supernatants were evaluated for LDH activity using the Cytotoxicity LDH Assay Kit-WST (Dojindo, Japan). The absorbance of all samples at a wavelength of $490 \mathrm{~nm}$ was recorded using a microplate reader. Low controls (untreated cells) and high controls (cells treated with lysis buffer) were used to calculate the cell mortality:

$$
\text { Cytotoxicity }(\%)=\frac{\text { test substance }- \text { low control }}{\text { high control }- \text { low control }} \times 100 \text {. }
$$

2.7. Measurement of Nanoparticle Uptake by Flow Cytometry. Particle uptake by macrophages was measured via flow cytometry. THP-1 cells were seeded into 24 -well cell culture plates at $2 \times 10^{5}$ cells per well with PMA overnight. Then, THP-1 cells were preincubated for $30 \mathrm{~min}$ with the following uptake inhibitors: $25 \mu \mathrm{M}$ cytochalasin $\mathrm{D}$ (CytD), used to disrupt actin-dependent phagocytosis [27]; $100 \mu \mathrm{M}$ amiloride (Ame), applied as an inhibitor of micropinocytosis [28]; and $25 \mu \mathrm{M}$ genistein (Gen) and $25 \mu \mathrm{M}$ chlorpromazine hydrochloride $(\mathrm{Cpz})$, used to inhibit caveolae- and clathrinmediated endocytosis, respectively [29]. Cells were subsequently exposed to $\mathrm{TiO}_{2}$ or Ta NPs at concentrations of 100 and $500 \mu \mathrm{g} / \mathrm{mL}(0.5 \mathrm{~mL} /$ well $)$ for 1 and $6 \mathrm{~h}$. The inhibitors were not removed during the uptake experiments. At the end of each time point, cells were trypsinized and centrifuged. The resulting cell pellet was resuspended in $200 \mu \mathrm{L}$ ice-cold PBS and analyzed with flow cytometry. Flow cytometry data were acquired using FACSCanto II using FACS-Diva 
software and analyzed using FlowJo software (all from BD Biosciences). Cell profiles were investigated through forward scatter (FSC) vs. side scatter (SSC) to exclude cell debris and free particles. Mean SSC was used as a measure of particle uptake. The increase in SSC, which was directly related to the cellular granularity, was analyzed as described previously [30]. SSC increases at $4^{\circ} \mathrm{C}$, which indicates the passive, energy-independent entrance of particles into cells, and a portion of particles adherent to macrophages' outer membranes were analyzed and subtracted from the data acquired at $37^{\circ} \mathrm{C}$.

2.8. Bright-Field Microscopy. THP-1 cells were differentiated as described above in a 12 -well chamber slide $(35 \mathrm{~mm})$ (ibidi, Germany) and treated for $24 \mathrm{~h}$ with standard culture medium, $\mathrm{TiO}_{2}$, and Ta NPs. Bright-field microscope images were taken using an IX81 microscope (Olympus).

\subsection{Measurement of Intracellular ROS Generation. The} generation of intracellular ROS was measured using $2^{\prime}, 7^{\prime}$ -dichlorodihydrofluorescein diacetate (DCFH-DA, SigmaAldrich). PMA-differentiated THP- 1 cells $\left(0.8 \times 10^{5}\right.$ cells/well in 96-well plates) were washed with warm PBS and then treated with $\mathrm{TiO}_{2}$ or Ta NPs at 50 to $500 \mu \mathrm{g} / \mathrm{mL}$ for $1,3,6$, and 24h. N-Acetyl-L-cysteine (NAC) was applied in some experiments to inhibit ROS production. For these tests, PMAdifferentiated THP-1 cells were pretreated with $10 \mathrm{mM} \mathrm{NAC}$ for $30 \mathrm{~min}$ and then stimulated with 100 or $500 \mu \mathrm{g} / \mathrm{mL}$ NPs for another 6 or $24 \mathrm{~h}$ in the presence of $10 \mathrm{mM} \mathrm{NAC}$. Then, serum-free RPMI medium containing $20 \mu \mathrm{M}$ DCFH-DA was added to the samples and controls for another $30 \mathrm{~min}$ under standard culturing conditions. Untreated controls were maintained for each time interval. Subsequently, cells were carefully washed twice with prewarmed PBS. The fluorescence intensity of the resulting fluorescent product dichlorofluorescein (DHF) was measured with a microplate reader at the excitation and emission wavelengths of 485 and $530 \mathrm{~nm}$, respectively.

2.10. Enzyme-Linked Immunosorbent Assay (ELISA). PMAdifferentiated THP- 1 cells $\left(0.8 \times 10^{5}\right.$ cells/well of a 96-well plate) were firstly primed with $200 \mathrm{ng} / \mathrm{mL}$ LPS (LPS-EK Ultrapure, InvivoGen) or incubated with standard culture medium for $3 \mathrm{~h}$. Then, LPS was removed, and macrophages were treated with particles for $1 \mathrm{~h}, 3 \mathrm{~h}, 6 \mathrm{~h}, 1 \mathrm{~d}, 3 \mathrm{~d}$, and $7 \mathrm{~d}$. NAC was applied in some experiments to inhibit ROS in THP-1 macrophages. For these tests, PMA-differentiated THP-1 cells were pretreated with $10 \mathrm{mM}$ NAC for $30 \mathrm{~min}$ following LPS priming and then stimulated with 100 or $500 \mu \mathrm{g} / \mathrm{mL}$ NPs for another $6 \mathrm{~h}$ in the presence of $10 \mathrm{mM}$ NAC. Cell-free supernatants were collected and centrifuged $\left(200 \times \mathrm{g}, 10 \mathrm{~min}, 4^{\circ} \mathrm{C}\right)$, and aliquots were stored at $-80^{\circ} \mathrm{C}$. TNF $\alpha$ and IL- $1 \beta$ were determined with an ELISA kit (R\&D Systems, Wiesbaden, Germany) according to the manufacturer's protocol, using a microplate ELISA reader.

2.11. Statistical Analysis. GraphPad Prism 7 software was used for statistical analysis. All values were expressed as the mean + SD. Student's $t$-test was used for comparisons between two groups, and one-way ANOVA was used to determine statistical differences between several groups. Differences were considered significant at ${ }^{*} p<0.05,{ }^{* *} p<0.01$, and ${ }^{* * *} p<0.001$

\section{Results}

3.1. Nanoparticle Characterization. SEM images of $\mathrm{TiO}_{2} \mathrm{NPs}$ (Figure 1(a)) and Ta NPs (Figure 1(b)) exhibited a spherical shape. $\mathrm{TiO}_{2}$ NPs were slightly more plate-like, with less rounded features. The average size of the $\mathrm{TiO}_{2}$ and Ta particles estimated from SEM images was $54.3 \pm 14.6 \mathrm{~nm}$ (Figure 1(c)) and $67.9 \pm 22.1 \mathrm{~nm}$ (Figure 1(d)), respectively. To further characterize the size distribution of particles in the liquid phase, $\mathrm{TiO}_{2}$ and $\mathrm{Ta}$ NPs were analyzed using dynamic light scattering (DLS). The hydrodynamic sizes of $\mathrm{TiO}_{2}$ and $\mathrm{Ta}$ NPs in $\mathrm{ddH}_{2} \mathrm{O}$, PBS, RPMI 1640 growth medium, and RPMI 1640 growth medium containing 10\% FBS are summarized in Supplementary Table 1. The DLS results demonstrated that both NPs had the tendency to form aggregates in different solutions. In addition, endotoxin levels were also tested in both groups by employing the LAL chromogenic assay. All NP samples did not show any contamination with endotoxins (Supplementary Figure 1), confirming that all particle samples could be considered endotoxin-free. To confirm NP purity, energy-dispersive X-ray (EDX) analyses were performed. The resulting EDX spectra of NPs indicated the presence of $\mathrm{Ti}$ and $\mathrm{Ta}$ as the main elements, with no indication of other selected elements (Supplementary Figure 2). Notably, our EDX data revealed some extent of oxidation of Ta NPs, which may be attributed to the formation of an oxide layer on the surface of Ta NPs during sample preparation.

\subsection{Bright-Field Microscopy of THP-1-Derived Macrophages} Exposed to $\mathrm{TiO}_{2}$ and $\mathrm{Ta}$ NPs. To observe the interaction between THP-1-derived macrophages and NPs, THP-1derived macrophages were exposed to culture medium (Figure 2(a)), $\mathrm{TiO}_{2}$ NPs (Figure 2(b)), and $\mathrm{Ta} \mathrm{NPs}$ (Figure 2(c)) for $24 \mathrm{~h}$, and bright-field images were taken. Bright-field images showed the presence of $\mathrm{TiO}_{2}$ and Ta NP agglomerates in the presence of THP-1-derived macrophages.

3.3. Analysis of the Cytotoxic Effect of $\mathrm{TiO}_{2}$ and $\mathrm{Ta} \mathrm{NPs}$ in THP-1-Derived Macrophages. THP-1-derived macrophages were exposed to $\mathrm{TiO}_{2}$ and Ta NPs using a concentration range of $20-500 \mu \mathrm{g} / \mathrm{mL}$. Cell viability was evaluated by CCK-8 assay. $\mathrm{TiO}_{2}$ NPs demonstrated no dose-dependent cytotoxicity until they reached a threshold of $200 \mu \mathrm{g} / \mathrm{mL}$ at 24 hours (Figure 3(a)). Beyond this limit, $\mathrm{TiO}_{2} \mathrm{NPs}$ significantly decreased macrophage viability in a dose- and time-dependent manner compared to untreated cells (Supplementary Figure 3(a)). In contrast, exposure of macrophages to $20-500 \mu \mathrm{g} / \mathrm{mL}$ Ta NPs did not result in a significant decrease in cell viability (Figure 3(b), Supplementary Figure 3(b)) until 7 days. Notably, at 24 and $48 \mathrm{~h}$ using $20 \mu \mathrm{g} / \mathrm{mL}$, cell viability was even slightly increased (Supplementary Figure 3(b)). As Ta's density is higher than that of $\mathrm{TiO}_{2}$, we also compared $100 \mu \mathrm{g} / \mathrm{mL} \mathrm{TiO}_{2}$ with $500 \mu \mathrm{g} / \mathrm{mL} \mathrm{Ta}$ 


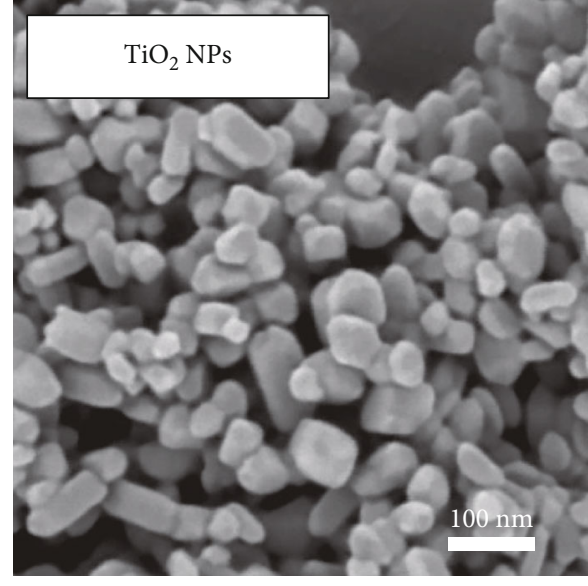

(a)

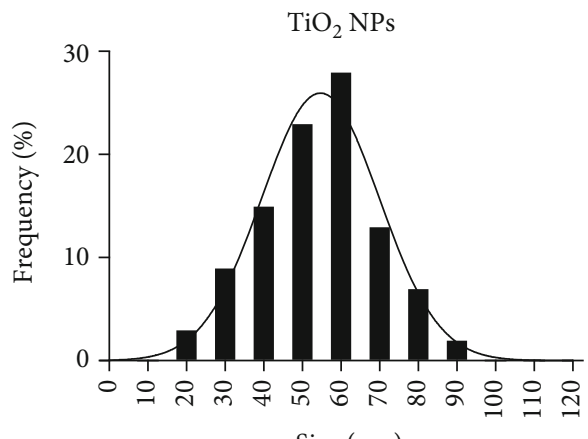

Size (nm)

(c)

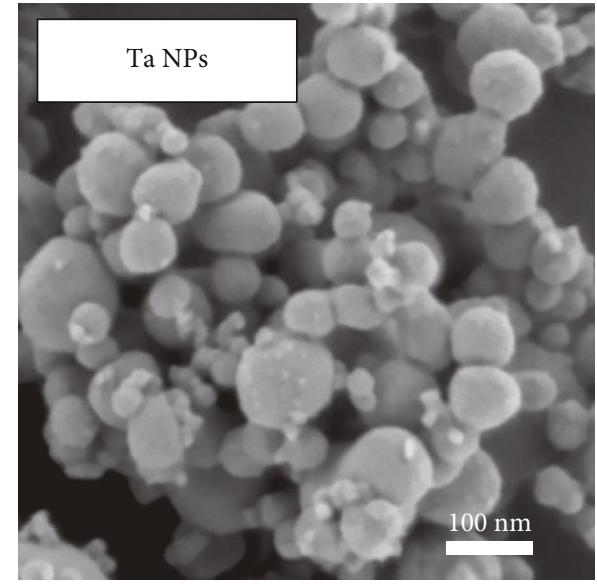

(b)

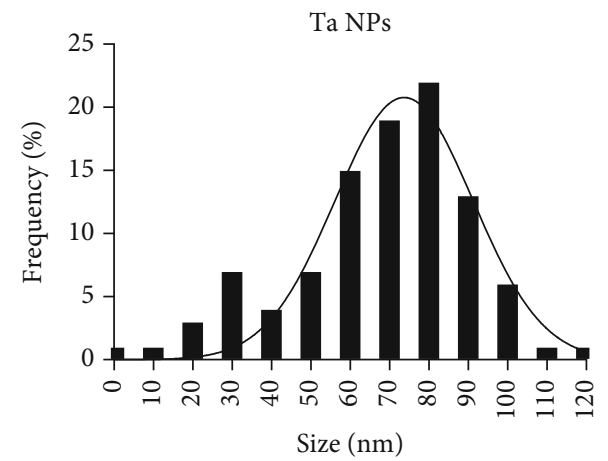

(d)

FIgure 1: Characterization of $\mathrm{TiO}_{2}$ and Ta NPs. (a, b) Scanning electron microscopic (SEM) images of TiO 2 NPs and Ta NPs. (c, d) Particle size distribution with Gaussian fitting of $\mathrm{TiO}_{2}$ NPs and Ta NPs was determined by randomly selecting 100 particles from the SEM images.

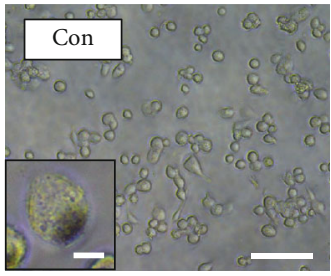

(a)

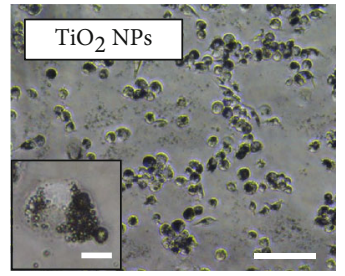

(b)

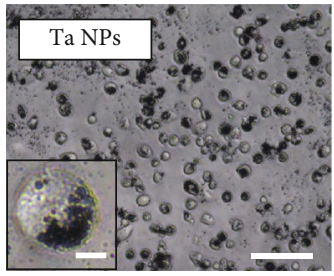

(c)

FIgURe 2: Bright-field microscope images of THP-1-derived macrophages treated with $\mathrm{TiO}_{2}$ and Ta NPs. THP-1-derived macrophages were cultured in the presence of (a) standard culture medium (Con: control), (b) $\mathrm{TiO}_{2} \mathrm{NPs}$, and (c) Ta NPs for 24 h. Bright-field images were taken $24 \mathrm{~h}$ after exposure. Scale bar: $100 \mu \mathrm{m}$ (overview) and $10 \mu \mathrm{m}$ (enlarged insert).

to compensate a potential bias by NP density. Similar to the direct comparison between the same NP concentrations, cells were still less viable in the presence of $100 \mu \mathrm{g} / \mathrm{mL} \mathrm{TiO}_{2}$ than in the presence of $500 \mu \mathrm{g} / \mathrm{mL}$ Ta NPs.

LDH is being released by cells as a consequence of cell membrane damage, and therefore, it is an indicator of irreversible cell death. As expected, the LDH release assay congruently supported our CCK-8 cell viability results. Compared to untreated cells, in the $\mathrm{TiO}_{2} \mathrm{NP}$ group, there was no appreciable cell death until 24 hours. Then, increasing cell death was observed in a dose- and time-dependent manner (Figure 3(c), Supplementary Figure 3(c)). In contrast, expo- sure of macrophages to $20-500 \mu \mathrm{g} / \mathrm{mL}$ Ta NPs for up to 7 days did not result in a significant increase in cell death (Figure 3(d), Supplementary Figure 3(d)). Overall, $\mathrm{TiO}_{2}$ and Ta NPs demonstrated good biocompatibility at low concentrations. At high concentrations, however, only $\mathrm{TiO}_{2} \mathrm{NPs}$ led to cytotoxicity.

3.4. Cellular Uptake and Internalization Routes of $\mathrm{TiO}_{2}$ and Ta NPs. Macrophages are phagocytic cells capable of sensing and internalizing particulate matters. To validate the uptake of $\mathrm{TiO}_{2}$ and Ta NPs, THP-1 macrophages were exposed to $\mathrm{TiO}_{2}$ and $\mathrm{Ta}$ NPs $(100$ and $500 \mu \mathrm{g} / \mathrm{mL}$ ) for 1 and $6 \mathrm{~h}$, and 


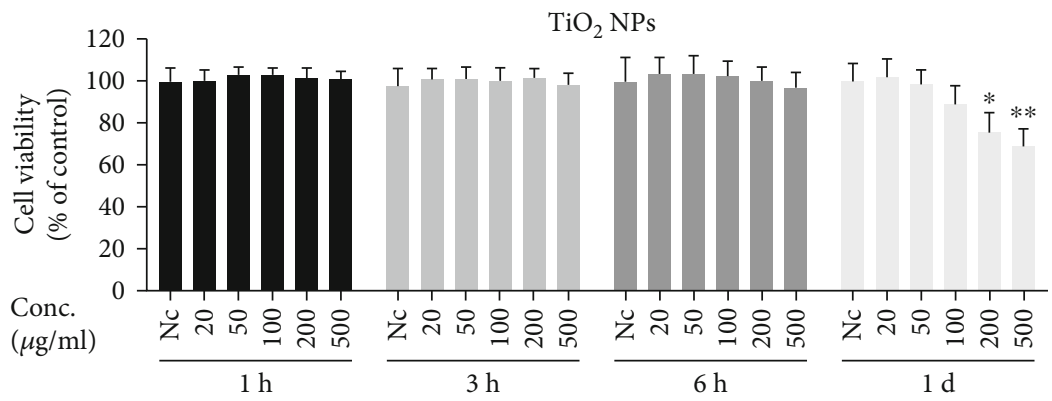

(a)

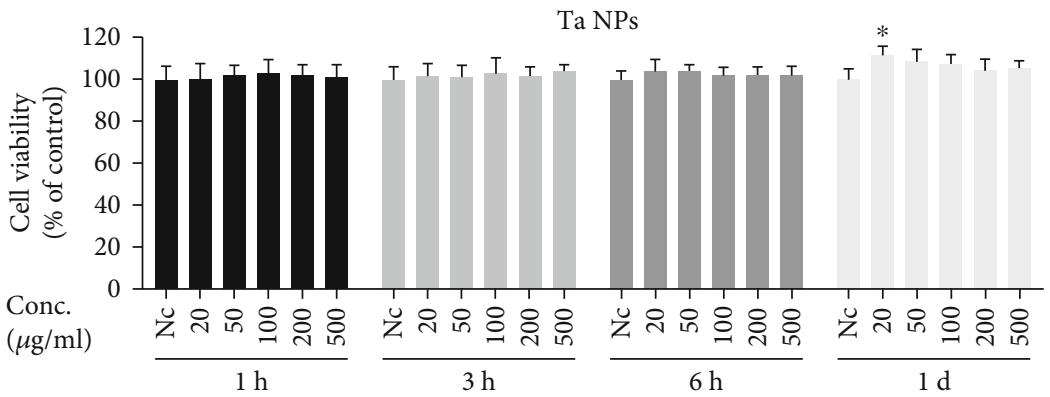

(b)



(c)

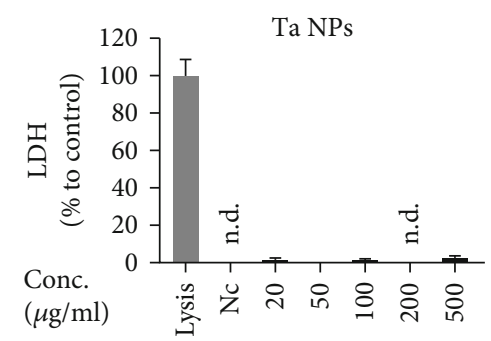

(d)

FIgure 3: Analysis of cytotoxic effects of $\mathrm{TiO}_{2}$ and Ta NPs on macrophages. (a, b) Cell viability was determined by CCK-8 assay at indicated time points. (c, d) Lactate dehydrogenase (LDH) leakage was evaluated by LDH assay after $24 \mathrm{~h}$. Viability and LDH release are normalized and expressed as mean $+\mathrm{SD}$ as percentage of untreated cells of three independent experiments $\left({ }^{*} p<0.05,{ }^{* *} p<0.01\right.$, and $\left.{ }^{* * *} p<0.001\right)$. n.d.: not detectable. Nc: nontreated control.

flow cytometry was used to quantify NP uptake. Flow cytometric analysis demonstrated that both $\mathrm{TiO}_{2}$ and Ta NPs significantly enhanced cell granularity, which was detected by SSC signals and can be used as a readout for NP uptake. We observed significantly lower SSC signals in the Ta NP group in contrast to the $\mathrm{TiO}_{2}$ group (Figure 4) at 1 and $6 \mathrm{~h}$, suggesting that THP-1-derived macrophages took up more $\mathrm{TiO}_{2}$ NPs than Ta NPs at the same concentration.

To determine possible uptake routes of $\mathrm{TiO}_{2}$ and Ta NPs, THP-1-derived macrophages were preincubated with different uptake inhibitors before NP exposure. Comparison of the FACS analysis data at 1 and $6 \mathrm{~h}$ demonstrated that the majority of the particles were internalized within the first hour (Figure 4). To ensure that the uptake inhibitors did not affect cell viability, cell viability was tested in the presence of different inhibitor concentrations up to 6 hours (Supplementary Figure 4).

As shown in Figures 4(a) and 4(b), the uptake of $\mathrm{TiO}_{2}$ and Ta NPs was significantly reduced after preincubation with $\mathrm{CytD}$, Ame, and Cpz, but not Gen, suggesting that mac- rophages take up $\mathrm{TiO}_{2}$ NPs via phagocytosis, macropinocytosis, and clathrin-dependent endocytosis. Similarly, Ta NPs were internalized through phagocytosis (Figures $4(\mathrm{c}$ ) and 4(d)). However, macropinocytosis and clathrin- and caveolin-mediated endocytosis inhibitors did not significantly reduce $\mathrm{Ta}$ uptake, indicating the absence of these mechanisms. In summary, the active internalization of $\mathrm{TiO}_{2}$ and Ta NPs were dominated by phagocytosis. $\mathrm{TiO}_{2} \mathrm{NP}$ uptake also involved macropinocytosis as well as clathrinmediated endocytosis, but to less extent. Caveolae-mediated endocytosis seems not to be involved in the uptake of both particles.

3.5. Ta NPs Trigger Less ROS Production than $\mathrm{TiO}_{2}$ NPs. NPinduced oxidative stress contributes to nanopathology [31]. In this study, the overall intracellular ROS elevation after NP challenge was examined using the probe $2^{\prime}, 7^{\prime}$-dichlorodihydrofluorescein diacetate (DCFH-DA). In our setup, as shown in Figure 5(a), $\mathrm{TiO}_{2}$ NPs dose-dependently induced robust intracellular ROS generation at different time points. 


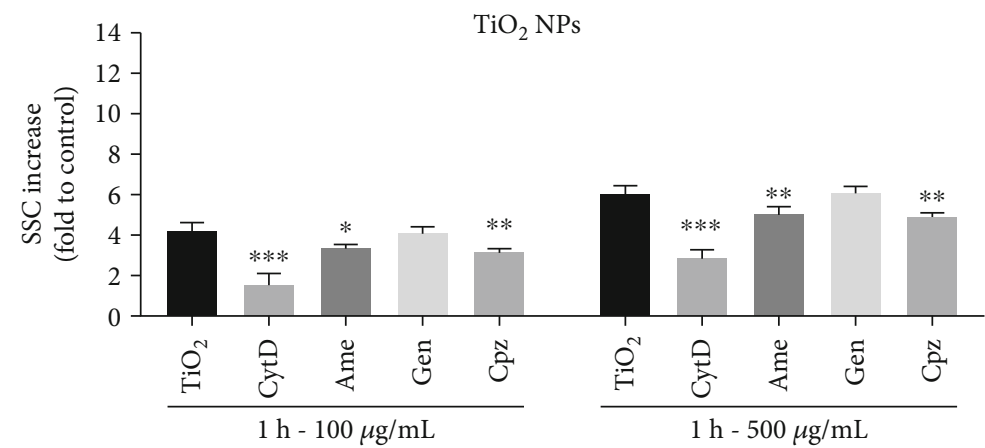

(a)

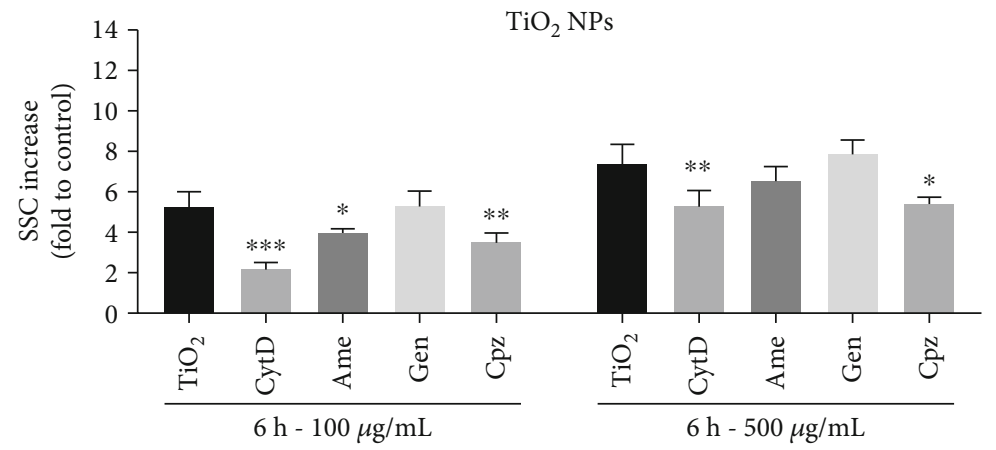

(b)

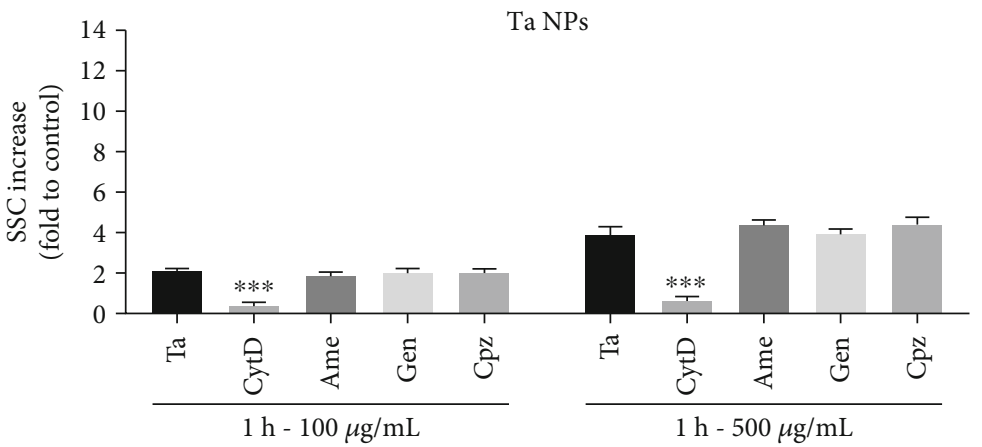

(c)

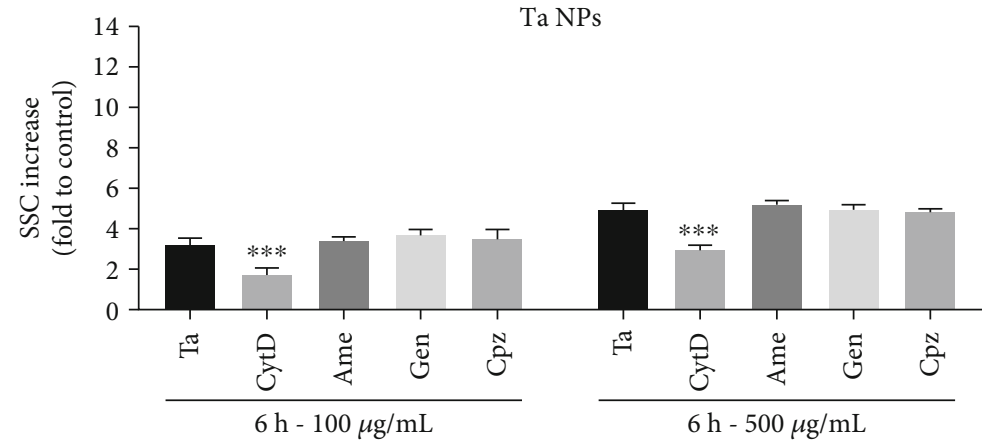

(d)

FIGURE 4: $\mathrm{TiO}_{2}$ and Ta NP internalization and their particle-specific uptake routes. THP-1-derived macrophages were pretreated with different uptake inhibitors for 30min and then exposed to (a) $\mathrm{TiO}_{2}$ and (b) $\mathrm{Ta} \mathrm{NPs}$ at 100 and $500 \mu \mathrm{g} / \mathrm{mL}$ for 1 and $6 \mathrm{~h}$. Changes in side scatter (SSC) were analyzed with flow cytometry. SSC changes at $4^{\circ} \mathrm{C}$ were subtracted, and data were expressed as mean + SD as fold of $\mathrm{NP}$-untreated cells $(\mathrm{Nc})$ of three independent experiments. Statistical differences were shown as ${ }^{*} p<0.05,{ }^{* *} p<0.01$, and ${ }^{* * *} p<0.001$ for inhibitor-treated groups vs. cells treated with particles only. 




(a)

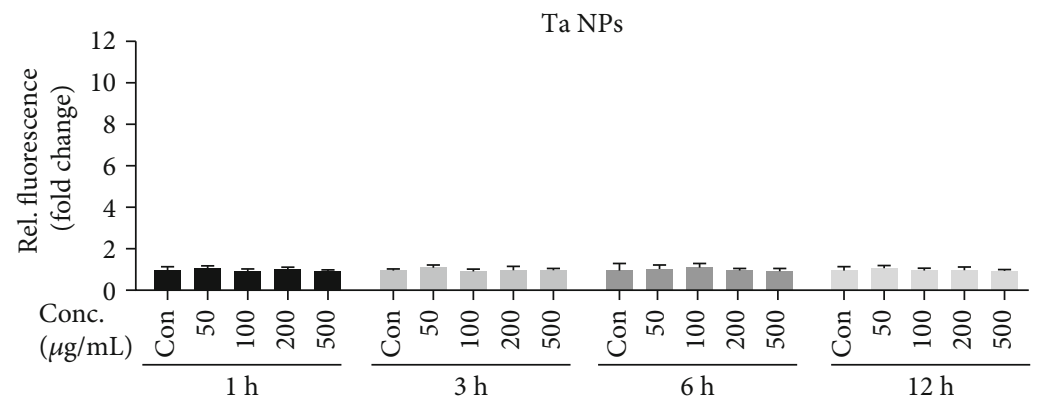

(b)

FIGURE 5: Endogenous ROS generation in THP-1-derived macrophages after $\mathrm{TiO}_{2}$ and $\mathrm{Ta} \mathrm{NP}$ exposure. THP-1-derived macrophages were stimulated with (a) $\mathrm{TiO}_{2}$ and (b) Ta NPs $(50-500 \mu \mathrm{g} / \mathrm{mL})$ for $1,3,6$, and $24 \mathrm{~h}$. Cells were stained with DCFH-DA $(20 \mu \mathrm{M})$ for $30 \mathrm{~min}$, and then fluorescence intensity was analyzed with a microplate reader. Fluorescence values are normalized and expressed as mean + SD as fold of untreated cells of three independent experiments $\left({ }^{*} p<0.05,{ }^{* *} p<0.01\right.$, and $\left.{ }^{* * *} p<0.001\right)$.

Comparison of these data showed that the majority of ROS was produced within the first hour after NP treatment. Notably, a reduction of endogenous ROS production was observed at 24 hours. This may result due to a decrease in cell viability (Figure 3(a)) at this time point. In contrast, Ta NPs induced negligible intracellular ROS elevation at different concentrations and incubation periods (Figure 5(b)). These results indicated that, compared to $\mathrm{TiO}_{2}$ NPs, Ta NPs are "inert" in generating ROS.

3.6. Ta NPs Exert Less Proinflammatory Activity than $\mathrm{TiO}_{2}$ NPs In Vitro. The wear particle-induced inflammatory response, mainly driven by macrophages, underlies the pathology of periprosthetic osteolysis and aseptic loosening [32]. Among all the proinflammatory mediators, $\mathrm{TNF} \alpha$ and IL- $1 \beta$ are the primary initiators and significant mediators of the wear particle-induced inflammatory cascade. Therefore, we investigated the proinflammatory effect of $\mathrm{TiO}_{2}$ and Ta NPs by evaluating their induction of TNF $\alpha$ and IL$1 \beta$ with or without LPS priming.

As shown in Figure 6, the production of TNF $\alpha$ is only weakly stimulated by $\mathrm{TiO}_{2} \mathrm{NPs}$ alone (Figure 6(a)), whereas, in LPS-primed macrophages, $\mathrm{TNF} \alpha$ release was markedly increased (Figure 6(b)). Further, simultaneous exposure of macrophages to $\mathrm{TiO}_{2}$ NPs and LPS dose-dependently enhanced TNF $\alpha$ production (Figure 6(b)), which is well beyond the levels observed with $\mathrm{TiO}_{2}$ NPs or LPS prime alone. Notably, $\mathrm{TiO}_{2} \mathrm{NPs}$ at low concentration $(100 \mu \mathrm{g} / \mathrm{mL})$ induced significantly more TNF $\alpha$ production than Ta NPs at high concentration $(500 \mu \mathrm{g} / \mathrm{mL})$ in LPS-primed macrophages. This suggests that $\mathrm{TiO}_{2}$ NPs synergized with LPS to stimulate the production of TNF $\alpha$. Whereas, Ta NPs did not exert such synergistic effect (Figure 6(b)).

Similar to TNF $\alpha$, little IL- $1 \beta$ secretion was detected in macrophages challenged with Ta NPs alone up to 24 hours. $\mathrm{TiO}_{2}$ NPs $(500 \mu \mathrm{g} / \mathrm{mL})$ stimulated a significantly higher IL$1 \beta$ level than Ta NPs in unprimed macrophages, starting at $3 \mathrm{~h}$ (Figure 6(c)). After LPS priming, much higher IL-1 $\beta$ levels were detected in $\mathrm{TiO}_{2}$-treated macrophages. $\mathrm{TiO}_{2}$ NPs further elevated IL- $1 \beta$ release in a time- and dosedependent manner (Figure 6(d)), higher than LPS or $\mathrm{TiO}_{2}$ NPs alone. In contrast to the TNF $\alpha$ result, the Ta NP groups stimulated a negligible IL- $1 \beta$ increase after LPS priming (Figure 6(d)) compared to the untreated group. This indicated that the IL- $1 \beta$ level was not entirely dependent on LPS. In summary, these results suggest that LPS aggravates inflammation in macrophages. Also, $\mathrm{TiO}_{2} \mathrm{NPs}$ synergized with the LPS effect to increase the production of TNF $\alpha$ and IL- $1 \beta$ while Ta NPs did not. Thus, $\mathrm{TiO}_{2}$ NPs possess a more substantial proinflammatory effect than Ta NPs.

3.7. Scavenging of ROS Attenuates $\mathrm{TiO}_{2}$-Induced Cell Death and Proinflammatory Cytokine Release. Intracellular ROS are key effectors in signal transduction and are proposed to be associated with cell death and inflammation. ROS generation has been proven crucial for NP-induced NLRP3 inflammasome activation and subsequent IL- $1 \beta$ release $[33,34]$. Therefore, we applied antioxidant NAC to prove the effect 


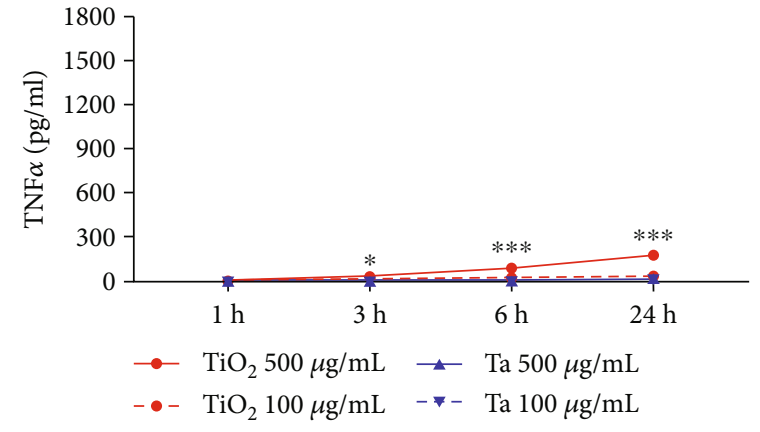

(a)

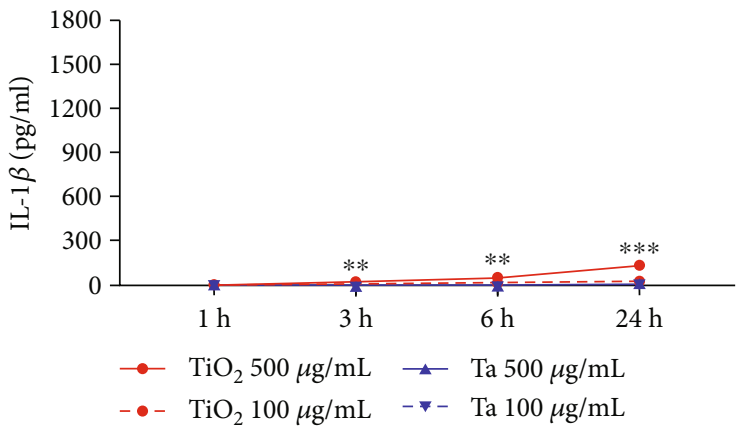

(c)

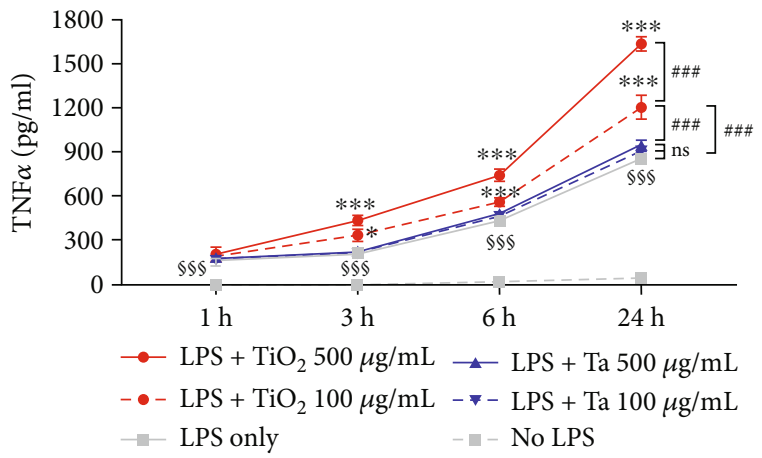

(b)

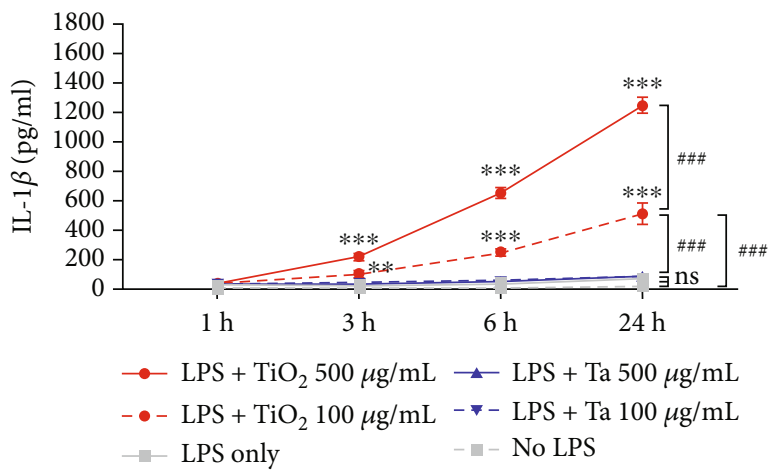

(d)

Figure 6: Proinflammatory potential of $\mathrm{TiO}_{2}$ and Ta NPs on THP-1-derived macrophages. THP-1-derived macrophages were primed with $200 \mathrm{ng} / \mathrm{mL}$ LPS for $3 \mathrm{~h}$, washed to remove the LPS, and then incubated with $\mathrm{TiO}_{2}$ or Ta NPs using the indicated doses for up to $24 \mathrm{~h}$. Release of (a, b) TNF $\alpha$ and (c, d) IL-1 $\beta$ were measured by ELISA. THP-1-derived macrophages without LPS stimulation were used as controls. * indicates significant differences of different time points of the $\mathrm{TiO}_{2} \mathrm{NP}$ group compared to the $\mathrm{TiO}_{2} \mathrm{NP} 1 \mathrm{~h}$ group $\left({ }^{*} p<0.05\right.$, ${ }^{* *} p<0.01$, and $\left.{ }^{* * *} p<0.001\right)$. \# indicates significant differences compared to the $\mathrm{TiO}_{2} \mathrm{NP}(100 \mu \mathrm{g} / \mathrm{mL})$ group at $24 \mathrm{~h}(\# \# \# p<0.001)$. $₫$ indicates significant LPS-mediated TNF $\alpha$ release compared to the untreated group $\left.{ }^{\$ \varsigma s} p<0.001\right)$.

of ROS on $\mathrm{TiO}_{2}$ NP-induced cell death and IL- $1 \beta$ release. NAC is a potent thiol-containing antioxidant that can act as a precursor of glutathione (GSH) and can also directly scavenge free radicals (e.g., $\mathrm{H}_{2} \mathrm{O}_{2}$ and $\mathrm{OH}^{-}$) [35]. As shown in Figures 7(a) and 7(b), the fluorescence intensity was lower in NAC-treated cells in comparison to cells treated with $\mathrm{TiO}_{2}$ NPs alone at 6 and 24h, indicating that NAC successfully antagonized ROS accumulation elicited by $\mathrm{TiO}_{2} \mathrm{NPs}$ in macrophages. Moreover, NAC treatment significantly mitigated cell death (Figure 6(c)) and potently blocked IL-1 $\beta$ release induced by $\mathrm{TiO}_{2}$ NPs (Figure 6(d)) after LPS prime. These results indicated that ROS inhibition by NAC could rescue $\mathrm{TiO}_{2} \mathrm{NP}$-induced nanotoxicity and mitigate IL- $1 \beta$ production in macrophages.

\section{Discussion}

Ta-based implants have been widely used in primary and revision TJA. Nevertheless, knowledge about the possible effect of their wear products on peri-implant cells remains limited to date. Therefore, understanding the local cellular responses to nanoscale orthopedic wear particles will provide a new area for comprehension of aseptic loosening and offers new scientifically based recommendations to better design suitable prosthetic interfaces and scaffolds. To the best of our knowledge, the present paper is the first in vitro analysis investigating Ta NPs and $\mathrm{TiO}_{2}$ metallic NPs side by side in terms of their biological responses on macrophages. We provide scientific evidence that Ta NPs are inert, nontoxic, and noninflammatory NPs in vitro. The results of this study offer novel evidence-based insights to further substantiate the clinical application of Ta-based implants [36, 37].

We found a slight but significant increase in macrophage viability in the presence of $20 \mu \mathrm{g} / \mathrm{mL}$ Ta NPs at 1 and 3 days. Similar results were found in the study by Wang et al. and Kang et al. showing that Ta NPs promote the proliferation of mouse MC3T3-E1 osteoblasts at low concentration (less than $20 \mu \mathrm{g} / \mathrm{mL}$ ) through the induction of autophagy [38, 39]. However, our CCK-8 and LDH results also demonstrated that Ta NPs, even when using higher concentrations (e.g., $50-500 \mu \mathrm{g} / \mathrm{mL}$ ) and longer incubation times (up to 7 days), still resulted in high cell viability, which ultimately supports their good biocompatibility. In contrast, $\mathrm{TiO}_{2} \mathrm{NPs}$ started to exhibit significant cytotoxicity at the 24-hour incubation time point. These aspects precisely show how important it is to fully characterize the cellular response of peri-implant cells to new implant materials and their resulting NPs. Therefore, the present study is of particular interest 

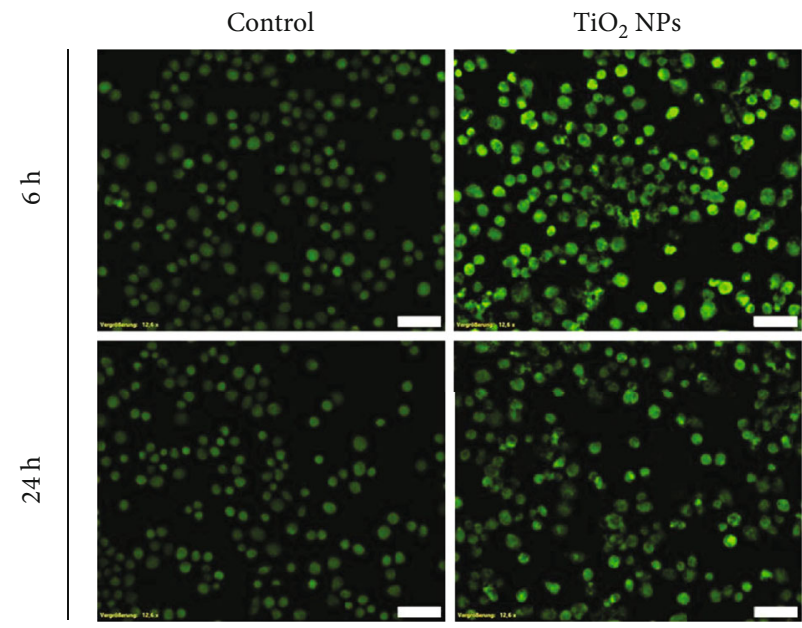

$\mathrm{TiO}_{2} \mathrm{NPs}+\mathrm{NAC}$

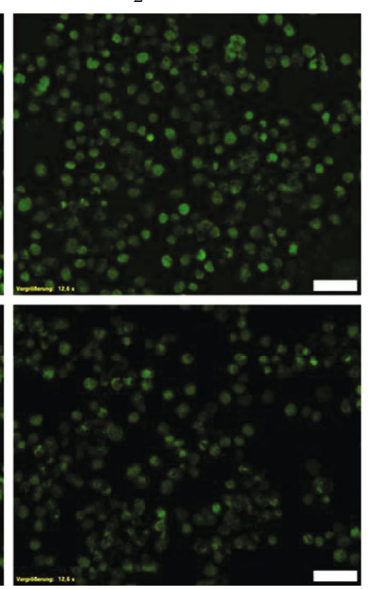

(a)

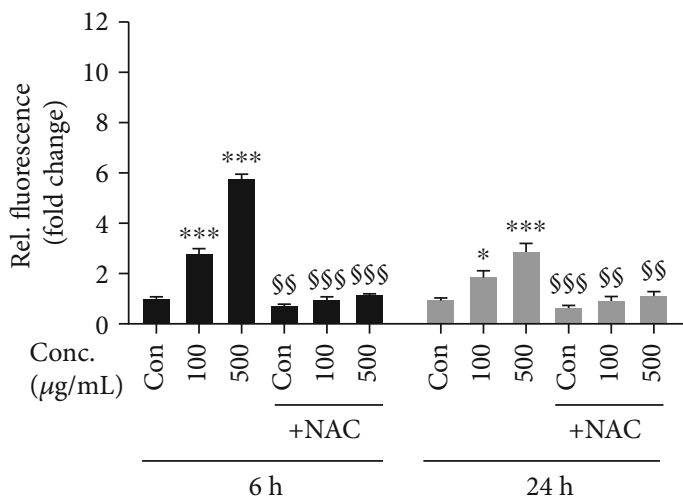

(b)

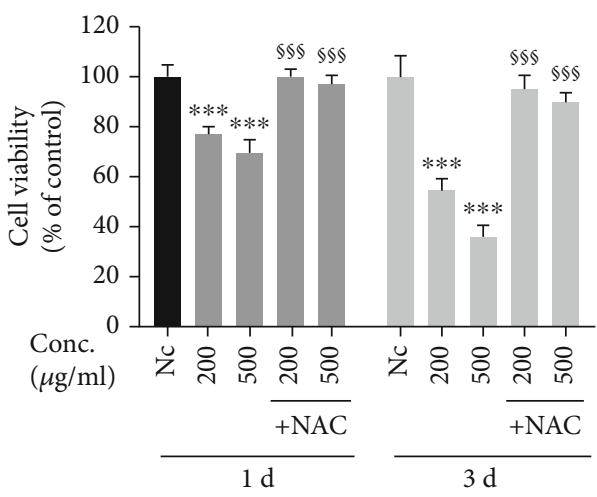

(c)

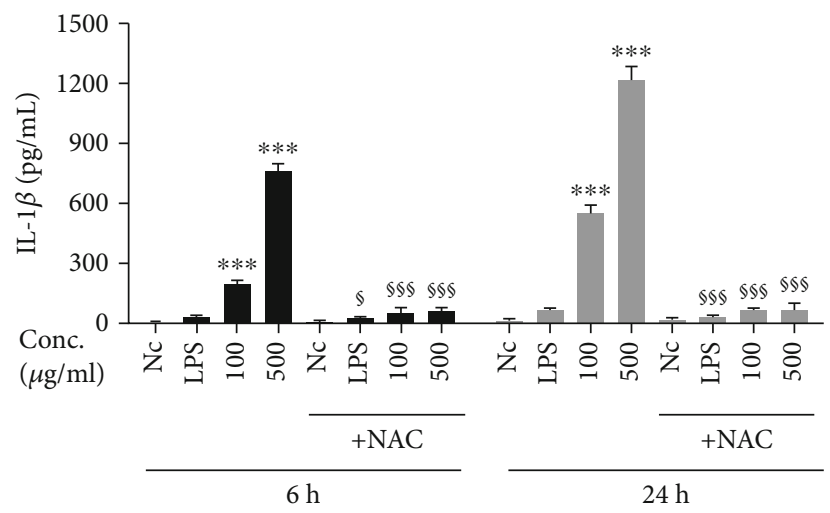

(d)

FIgure 7: Protective role of ROS scavenger (NAC) on $\mathrm{TiO}_{2}$ NP-induced cell death and IL- $1 \beta$ release. LPS-primed macrophages were preincubated for $30 \mathrm{~min}$ with/without NAC $(5 \mathrm{mM})$, and then cotreated with $\mathrm{TiO}_{2} \mathrm{NPs}$ at the indicated doses for 6 and $24 \mathrm{~h}$. (a) Following exposure, cells were incubated with DCFH-DA $(20 \mu \mathrm{M})$ for $30 \mathrm{~min}$ at $37^{\circ} \mathrm{C}$, and ROS production was detected by fluorescence microscopy (20x). Scale bar: $50 \mu \mathrm{m}$. (b) Relative quantification of ROS generation (fold change). The protective role of NAC on (c) cell viability and release of (d) IL- $1 \beta$ were measured by CCK- 8 and ELISA, respectively. Data are presented as mean + SD of three identical experiments performed in three replicates. ${ }^{*}$ indicates significant difference as compared to the control $\left({ }^{*} p<0.05,{ }^{* *} p<0.01\right.$, and $\left.{ }^{* * *} p<0.001\right)$; $\S$ indicates significant inhibitory effect of NAC on cell death and proinflammatory cytokine generation $\left({ }^{\S} p<0.05\right.$, ${ }^{\S \S} p<0.01$, and $\left.{ }^{s \varsigma} p<0.001\right)$.

as it provides the first comparative analysis showing that $\mathrm{Ta}$ NPs induced less cytotoxicity in macrophages than NPs stemming from Ti implants.
Phagocytosis and endocytosis are responsible for the uptake and clearance of particles [27, 40]. However, to date, the mechanistic nature of $\mathrm{TiO}_{2}$ and $\mathrm{Ta} \mathrm{NP}$ internalization 
in human macrophages remains obscure. Our study demonstrated that active $\mathrm{Ta}$ and $\mathrm{TiO}_{2} \mathrm{NP}$ internalization by macrophages is mainly driven by phagocytosis. Further, $\mathrm{TiO}_{2}$ internalization is also mediated, to a lesser extent, by clathrin-dependent endocytosis and micropinocytosis. These results are supported by previous studies, which have shown that $\mathrm{TiO}_{2}$ particle internalization is mediated by phagocytosis and endocytosis in glial cells [28], H9c2 rat cardiomyoblasts [27], and rodent macrophages [41, 42]. The multiple uptake pathways of $\mathrm{TiO}_{2}$ NPs may partially explain why they were internalized more efficiently and why they induce more robust cytotoxicity, oxidative stress, and inflammatory cytokines compared to Ta NPs under the same conditions.

Increased bone resorption due to chronic inflammatory responses from wear particle-challenged macrophages underlies the pathogenesis of periprosthetic osteolysis [21]. TNF $\alpha$ is a master cytokine during inflammation and a potent inducer of other proinflammatory chemokines and cytokines. When focussing on inflammatory cytokines, the Ta-based surface seems to exert an anti-inflammatory effect compared to the Ti-based surface [43], suggesting that Ta substrates are more biologically inert and may provide a more favorable environment when applied as biomaterial. However, other studies reported that Ta-based surfaces could be more inflammatory than Ti-based [44] surfaces. This discrepancy may be attributed to the difference in surface elemental composition, modification methods, and culturing model (in vitro, in vivo, and ex vivo).

Our results demonstrated that $\mathrm{Ta}$ and $\mathrm{TiO}_{2} \mathrm{NPs}$ induced slight TNF $\alpha$ production without LPS priming. After exposure to LPS, which mimicked the situation of a low-grade infection in addition to the presence of wear particles, TNF $\alpha$ secretion increased over time in both NP groups. This is mainly because LPS can stimulate TNF $\alpha$ production through binding to Toll-like receptor- 4 and subsequent activation of transcription factor NF- $\kappa \mathrm{B}$. It is important to note that the TNF level elevation over time in the LPS plus Ta NP group is insignificant compared to that of the LPS-only group. In contrast, $\mathrm{TiO}_{2}$ NPs act synergistically with LPS and further elevate TNF $\alpha$ production. This synergistic effect directly leads to a significantly higher amount of TNF $\alpha$ in the $\mathrm{TiO}_{2}$ NP group $(100 \mu \mathrm{g} / \mathrm{mL})$ compared to the Ta NP group (100 and $500 \mu \mathrm{g} / \mathrm{mL}$ ), indicating that, in the form of nanoscale particles, $\mathrm{Ta}$ is less proinflammatory than $\mathrm{Ti}$ particles.

IL- $1 \beta$ is considered an essential proinflammatory mediator driving osteolysis at the bone-implant interface. Recent studies demonstrated that orthopedic wear particles mediate IL- $1 \beta$ release via activation of the NLRP3 inflammasome [ 45 , 46], whose activation is a two-step process requiring both priming (e.g., bacterial LPS) and activation signals (e.g., nigericin, silica crystal, and wear particles). Supporting these data, dramatic elevation of IL- $1 \beta$ secretion was only observed after LPS priming and $\mathrm{TiO}_{2}$ NPs. This indicated that both LPS priming and wear particles are required to license NLRP3 inflammasome activation [47]. Infection (in our case simulated by LPS) thus could be a potent inducer of inflammation, dramatically amplifying wear particle-induced inflammation and, therefore, could be a risk factor for implant loosening. The current results are in line with previ- ous data which showed that LPS contributes to the biological activity of wear particles by increasing the proinflammatory cytokine production in macrophages $[46,48]$. It is important to note that $500 \mu \mathrm{g} / \mathrm{mL}$ Ta NPs induced similar SSC elevation to that of $100 \mu \mathrm{g} / \mathrm{mL} \mathrm{TiO}_{2}$ NPs at 6 hours. However, Ta NPs stimulated almost no elevation of IL- $1 \beta$ in the supernatant over time, even after priming with LPS. This, again, supported the noninflammatory property of Ta NPs compared to $\mathrm{TiO}_{2}$ NPs. It also suggests that, in the context of periimplant infection, Ta-based implants may help limit the peri-implant inflammation, or could be a proper choice in revision surgery due to periprosthetic joint infection (PJI).

Interestingly, $\mathrm{TiO}_{2} \mathrm{NPs}$ alone induced a low but significant elevation of IL- $1 \beta$ over time. Given that all our particle samples were endotoxin-free, this effect may be due to other priming signals, such as TNF $\alpha$ [49] (Figure 6(a)). This fits the clinical picture in which increased values of IL- $1 \beta$ are detected together with $\mathrm{TNF} \alpha$ in chronic low-grade periimplant inflammation without any sign of infection.

Oxidative stress has been proposed to play a role in nanotoxicology and inflammatory reactions [31, 50]. Previous studies have revealed that, compared to Ti substrates, Ta substrates demonstrate lower ROS generation in osteoblasts and bone marrow stromal cells and, therefore, exhibit better cellular viability and osteoinductivity [23, 51]. In our study, we found that $\mathrm{TiO}_{2}$ NPs induced robust ROS elevation while Ta NPs induced negligible amounts of ROS. This distinct difference in ROS-generating potential could be mainly attributed to the difference in particle type. Nevertheless, we cannot exclude that there are other potential influential factors, e.g., uptake efficiency, size, morphology, and oxidation extent. Furthermore, $\mathrm{TiO}_{2}$ NPs demonstrated higher cytotoxicity and induced higher inflammatory cytokines than Ta NPs. Thus, it is feasible to speculate that the difference in cytotoxicity and IL- $1 \beta$ release is due to differences in NPs' oxidative potential. We further proved this notion using NAC, a general ROS scavenger. Our study demonstrated that scavenging ROS with NAC abrogated $\mathrm{TiO}_{2} \mathrm{NP}$-induced ROS production in macrophages. Furthermore, NAC mitigated $\mathrm{TiO}_{2} \mathrm{NP}$ induced cell death and abrogated IL- $1 \beta$ release. Similar results were found in previous studies in which ROS suppression by NAC protected cells from cell death $[52,53]$ and IL- $1 \beta$ release [54-57] in response to ROS-generating NPs. This further proved that ROS depression can mitigate NP-induced cell death and IL-1 $\beta$ production and, therefore, may alleviate peri-implant tissue and inflammation. Although NAC has been successfully applied in previous studies as a ROS scavenger, it has multiple effects on cells $[58,59]$, which complicates the interpretation of the results. More specific ROS inhibitors are needed in the future to identify the ROS source. Collectively, the differences in inducing oxidative stress could explain why Ta NPs are relatively inert opposed to promoting cell death and inflammation as previously described for $\mathrm{TiO}_{2}$, or other widely used NPs such as silica NPs [60]. Furthermore, targeting ROS may serve as a therapeutic way to mitigate wear particle-induced chronic inflammation and prosthetic loosening. However, the exact source of ROS, e.g., mitochondrial and NADPH oxidase, and their relative contribution to NPinduced inflammation, need further characterization. 


\section{Conclusions}

For the first time in this study, we examined macrophages' cellular response to nanoscale $\mathrm{Ta}$ and Ti particles in vitro. We found that $\mathrm{Ta}$, in the form of nanoscale particles, was "bioinert" and induced less cytotoxicity, ROS production, and inflammatory response compared to $\mathrm{TiO}_{2} \mathrm{NPs}$. Thus, when applied as TJA biomaterials, Ta-based implants may provide a more favorable peri-implant biological environment and less potential to contribute to aseptic loosening than $\mathrm{Ti}$ implants. Considering that multiple biomaterials have been applied in the TJA field, comparing Ta particles with additional other particle types (e.g., polyethylene, cobalt, and chromium) should be included in future studies to assess the value of switching from conventional implants to $\mathrm{Ta}-$ based implants.

\section{Data Availability}

The data used to support the findings of this study are available from the corresponding authors upon request.

\section{Conflicts of Interest}

The authors declare that there is no conflict of interest regarding the publication of this article.

\section{Authors' Contributions}

Koroush Kabir and Frank A. Schildberg contributed equally to this work.

\section{Acknowledgments}

We appreciate the technical assistance from Ms. Cäcilia Hilgers, Mr. Werner Masson, and Mr. Knut Wichterich. Furthermore, we would like to acknowledge the assistance of the Flow Cytometry Core Facility at the Institute of Experimental Immunology, Medical Faculty at the University of Bonn. We would also like to acknowledge the assistance of the Microscopy Core Facility of the Medical Faculty within the Bonn Technology Campus Life Sciences, University of Bonn as well as the EDX-Facility at the Department of Horticultural Sciences, Faculty of Agriculture, University of Bonn. Furthermore, we thank Dr. Shu Chen for her support and help in this project. We thank the China Scholarship Council (CSC) for the financial support of this work.

\section{Supplementary Materials}

Supplementary Table 1: hydrodynamic radius measured by DLS. $\mathrm{TiO}_{2}$ and $\mathrm{Ta}$ nanoparticles (NPs) were dispersed in $\mathrm{ddH}_{2} \mathrm{O}$, PBS, RPMI 1640, and RPMI 1640 containing 10\% FBS at $250 \mu \mathrm{g} / \mathrm{mL}$. Hydrodynamic radius (nm) was determined by DLS, and data from major peaks were presented. Supplementary Figure 1: endotoxin contamination of $\mathrm{TiO}_{2}$ and Ta NPs. Quantitative evaluation of endotoxin contamination was determined by an LAL endotoxin assay kit. Data were representative of three independent experiments. The endotoxin level was calculated according to the standard curve. n.d.: not detectable. Supplementary Figure 2: spectral intensities of the $\mathrm{Ta}$ (a) and $\mathrm{TiO}_{2}$ (b) samples observed in the energy-dispersive $\mathrm{X}$-ray (EDX) analysis system. The spectra were analyzed in high vacuum (accelerating voltage: $20 \mathrm{kV}$; spot size: 5.5). No contamination of other elements were observed. Supplementary Figure 3: cytotoxic effects of $\mathrm{TiO}_{2}$ and Ta NPs on macrophages from 1 day to 7 days. (a, b) Cell viability was determined by CCK-8 assay at indicated time points. (c, d) Lactate dehydrogenase (LDH) leakage was evaluated by LDH assay after $24 \mathrm{~h}$. Viability and $\mathrm{LDH}$ release are normalized and expressed as mean $+\mathrm{SD}$ as percentage of untreated cells of three independent experiments $\left({ }^{*} p<0.05,{ }^{* *} p<0.01\right.$, and $\left.{ }^{* * *} p<0.001\right)$. n.d.: not detectable. Nc: nontreated control. Supplementary Figure 4: cytotoxic effects of inhibitors on macrophages. Macrophages were incubated with different concentrations of uptake inhibitors, and cell viability was evaluated by CCK- 8 assay. Viability is normalized and expressed as mean $+\mathrm{SD}$ as the percentage of untreated cells of three independent experiments. ${ }^{*} p<0.05$, compared with control. (Supplementary Materials)

\section{References}

[1] O. N. Schipper, S. L. Haddad, P. Pytel, and Y. Zhou, "Histological analysis of early osteolysis in total ankle arthroplasty," Foot \& Ankle International, vol. 38, no. 4, pp. 351-359, 2016.

[2] T. Schmalzried, M. Jasty, and W. H. Harris, "Periprosthetic bone loss in total hip arthroplasty: polyethylene wear debris and the concept of the effective joint space," The Journal of bone and joint surgery, vol. 74, no. 6, pp. 849-863, 1992.

[3] K. Hirakawa, T. W. Bauer, B. N. Stulberg, and A. H. Wilde, "Comparison and quantitation of wear debris of failed total hip and total knee arthroplasty," Journal of Biomedical Materials Research, vol. 31, no. 2, pp. 257-263, 1996.

[4] K. J. Margevicius, T. W. Bauer, J. T. McMahon, S. A. Brown, and K. Merritt, "Isolation and characterization of debris in membranes around total joint prostheses," JBJS, vol. 76, no. 11, pp. 1664-1675, 1994.

[5] D. J. Hall, R. Pourzal, J. J. Jacobs, and R. M. Urban, "Metal wear particles in hematopoietic marrow of the axial skeleton in patients with prior revision for mechanical failure of a hip or knee arthroplasty," Journal of Biomedical Materials Research Part B: Applied Biomaterials, vol. 107, no. 6, pp. 1930-1936, 2018.

[6] I. Polyzois, D. Nikolopoulos, I. Michos, E. Patsouris, and S. Theocharis, "Local and systemic toxicity of nanoscale debris particles in total hip arthroplasty," Journal of Applied Toxicology, vol. 32, no. 4, pp. 255-269, 2012.

[7] A. C. Paulus, K. Ebinger, X. Cheng et al., "Local biological reactions and pseudotumor-like tissue formation in relation to metal wear in a murine in vivo model," BioMed Research International, vol. 2019, 10 pages, 2019.

[8] D. R. Bijukumar, A. Segu, J. C. Souza et al., "Systemic and local toxicity of metal debris released from hip prostheses: a review of experimental approaches," Nanomedicine: Nanotechnology, Biology and Medicine, vol. 14, no. 3, pp. 951963, 2018.

[9] N. A. Beckmann, R. G. Bitsch, M. Schonhoff, K.-A. Siebenrock, M. Schwarze, and S. Jaeger, "Comparison of the primary stability of porous tantalum and titanium acetabular revision constructs," Materials, vol. 13, no. 7, p. 1783, 2020. 
[10] H. Abdelaziz, R. Jaramillo, T. Gehrke, M. Ohlmeier, and M. Citak, "Clinical survivorship of aseptic revision total knee arthroplasty using hinged knees and tantalum cones at minimum 10-year follow-up," The Journal of Arthroplasty, vol. 34, no. 12, pp. 3018-3022, 2019.

[11] M. T. Houdek, P. C. Ferguson, M. P. Abdel et al., "Comparison of porous tantalum acetabular implants and Harrington reconstruction for metastatic disease of the acetabulum," Journal of Bone and Joint Surgery, vol. 102, no. 14, pp. 1239-1247, 2020.

[12] G. Mohandas, N. Oskolkov, M. T. McMahon, P. Walczak, and M. Janowski, "Porous tantalum and tantalum oxide nanoparticles for regenerative medicine," Acta Neurobiologiae Experimentalis, vol. 74, no. 2, pp. 188-196, 2014.

[13] M. Stiehler, M. Lind, T. Mygind et al., "Morphology, proliferation, and osteogenic differentiation of mesenchymal stem cells cultured on titanium, tantalum, and chromium surfaces," Journal of Biomedical Materials Research Part A, vol. 86A, no. 2, pp. 448-458, 2008.

[14] Q. Wang, H. Zhang, Q. Li et al., "Biocompatibility and osteogenic properties of porous tantalum," Experimental and Therapeutic Medicine, vol. 9, no. 3, pp. 780-786, 2015.

[15] R. M. Meneghini, C. Meyer, C. A. Buckley, A. D. Hanssen, and D. G. Lewallen, "Mechanical stability of novel highly porous metal acetabular components in revision total hip arthroplasty," The Journal of Arthroplasty, vol. 25, no. 3, pp. 337341, 2010.

[16] D. R. Jenkins, A. N. Odland, R. J. Sierra, A. D. Hanssen, and D. G. Lewallen, "Minimum five-year outcomes with porous tantalum acetabular cup and augment construct in complex revision total hip arthroplasty," The Journal of Bone and Joint Surgery, vol. 99, no. 10, p. e49, 2017.

[17] J. Schoon, S. Geißler, J. Traeger et al., "Multi-elemental nanoparticle exposure after tantalum component failure in hip arthroplasty: in-depth analysis of a single case," Nanomedicine: Nanotechnology, Biology and Medicine, vol. 13, no. 8, pp. 2415-2423, 2017.

[18] G. C. Babis, N. A. Stavropoulos, G. Sasalos, M. OchsenkuehnPetropoulou, and P. Megas, "Metallosis and elevated serum levels of tantalum following failed revision hip arthroplasty-a case report," Acta Orthopaedica, vol. 85, no. 6, pp. 677-680, 2014.

[19] A. Brüggemann, H. Mallmin, M. Bengtsson, and N. P. Hailer, "Safety of use of tantalum in total hip arthroplasty," JBJS, vol. 102 , no. 5, pp. 368-374, 2020.

[20] E. Ingham and J. Fisher, "The role of macrophages in osteolysis of total joint replacement," Biomaterials, vol. 26, no. 11, pp. 1271-1286, 2005.

[21] C. Nich, Y. Takakubo, J. Pajarinen et al., "Macrophages-key cells in the response to wear debris from joint replacements," Journal of biomedical materials research Part A, vol. 101, no. 10, pp. 3033-3045, 2013.

[22] N. J. Hallab and J. J. Jacobs, "Chemokines associated with pathologic responses to orthopedic implant debris," Frontiers in Endocrinology, vol. 8, p. 5, 2017.

[23] M. Lu, P. Wu, X. Guo, L. Yin, H. Cao, and D. Zou, “Osteoinductive effects of tantalum and titanium on bone mesenchymal stromal cells and bone formation in ovariectomized rats," European Review for Medical and Pharmacological Sciences, vol. 22, no. 21, pp. 7087-7104, 2018.

[24] X. Dou, X. Wei, G. Liu et al., "Effect of porous tantalum on promoting the osteogenic differentiation of bone marrow mes- enchymal stem cells in vitro through the MAPK/ERK signal pathway," Journal of Orthopaedic Translation, vol. 19, pp. 81-93, 2019.

[25] L.-Y. Shi, A. Wang, F.-Z. Zang, J.-X. Wang, X.-W. Pan, and H.J. Chen, "Tantalum-coated pedicle screws enhance implant integration," Colloids and Surfaces B: Biointerfaces, vol. 160, pp. 22-32, 2017.

[26] H. Ding, Z. Zhu, T. Tang, D. Yu, B. Yu, and K. Dai, “Comparison of the cytotoxic and inflammatory responses of titanium particles with different methods for endotoxin removal in RAW264.7 macrophages," Journal of Materials Science: Materials in Medicine, vol. 23, no. 4, pp. 1055-1062, 2012.

[27] E. Huerta-García, M. D. P. Ramos-Godinez, A. López-Saavedra et al., "Internalization of titanium dioxide nanoparticles is mediated by actin-dependent reorganization and clathrinand dynamin-mediated endocytosis in H9c2 rat cardiomyoblasts," Chemical Research in Toxicology, vol. 32, no. 4, pp. 578-588, 2019.

[28] E. Huerta-García, S. G. Márquez-Ramírez, M. . P. Ramos-Godinez et al., "Internalization of titanium dioxide nanoparticles by glial cells is given at short times and is mainly mediated by actin reorganization-dependent endocytosis," Neurotoxicology, vol. 51, pp. 27-37, 2015.

[29] J. Linares, M. C. Matesanz, M. Vila et al., "Endocytic mechanisms of graphene oxide nanosheets in osteoblasts, hepatocytes and macrophages," ACS Applied Materials \& Interfaces, vol. 6, no. 16, pp. 13697-13706, 2014.

[30] J. Park, M. K. Ha, N. Yang, and T. H. Yoon, "Flow cytometrybased quantification of cellular Au nanoparticles," Analytical Chemistry, vol. 89, no. 4, pp. 2449-2456, 2017.

[31] P. P. Fu, Q. Xia, H.-M. Hwang, P. C. Ray, and H. Yu, "Mechanisms of nanotoxicity: generation of reactive oxygen species," Journal of Food and Drug Analysis, vol. 22, no. 1, pp. 64-75, 2014.

[32] S. B. Goodman and J. Gallo, "Periprosthetic osteolysis: mechanisms, prevention and treatment," Journal of Clinical Medicine, vol. 8, no. 12, p. 2091, 2019.

[33] S. Feng, Z. Zhang, Y. Mo et al., "Activation of NLRP3 inflammasome in hepatocytes after exposure to cobalt nanoparticles: the role of oxidative stress," Toxicology In Vitro, vol. 69, p. 104967, 2020.

[34] M. Zhu, L. Du, R. Zhao et al., "Cell-penetrating nanoparticles activate the inflammasome to enhance antibody production by targeting microtubule-associated protein 1-light chain 3 for degradation," ACS Nano, vol. 14, no. 3, pp. 3703-3717, 2020.

[35] N. Daems, S. Penninckx, I. Nelissen et al., "Gold nanoparticles affect the antioxidant status in selected normal human cells," International Journal of Nanomedicine, vol. Volume 14, pp. 4991-5015, 2019.

[36] Z. Miao, P. Liu, Y. Wang et al., "PEGylated tantalum nanoparticles: a metallic photoacoustic contrast agent for multiwavelength imaging of tumors," Small, vol. 15, no. 41, article 1903596, 2019.

[37] H. Zhu, X. Ji, H. Guan et al., "Tantalum nanoparticles reinforced polyetheretherketone shows enhanced bone formation," Materials Science and Engineering: C, vol. 101, pp. 232242, 2019.

[38] P. Wang, P. Qiao, H. Xing, R. Zhang, E. Lingling, and H. Liu, "Cytotoxicity, oxidative stress, and autophagy effects of tantalum nanoparticles on MC3T3-E1 mouse osteoblasts," Journal of Nanoscience and Nanotechnology, vol. 20, no. 3, pp. 14171424,2020 
[39] C. Kang, L. Wei, B. Song et al., "Involvement of autophagy in tantalum nanoparticle-induced osteoblast proliferation," International Journal of Nanomedicine, vol. Volume 12, pp. 43234333, 2017.

[40] M. Geiser, "Update on macrophage clearance of inhaled micro- and nanoparticles," Journal of Aerosol Medicine and Pulmonary Drug Delivery, vol. 23, no. 4, pp. 207-217, 2010.

[41] A. M. Scherbart, J. Langer, A. Bushmelev et al., "Contrasting macrophage activation by fine and ultrafine titanium dioxide particles is associated with different uptake mechanisms," Particle and fibre toxicology, vol. 8, no. 1, p. 31, 2011.

[42] Q. Chen, N. Wang, M. Zhu et al., " $\mathrm{TiO}_{2}$ nanoparticles cause mitochondrial dysfunction, activate inflammatory responses, and attenuate phagocytosis in macrophages: a proteomic and metabolomic insight," Redox Biology, vol. 15, pp. 266-276, 2018.

[43] Q. Huang, X. Li, T. A. Elkhooly et al., "The osteogenic, inflammatory and osteo-immunomodulatory performances of biomedical Ti-Ta metal-metal composite with $\mathrm{Ca}$ - and $\mathrm{Si}$ containing bioceramic coatings," Colloids and Surfaces B: Biointerfaces, vol. 169, pp. 49-59, 2018.

[44] C. Yang, J. Li, C. Zhu et al., "Advanced antibacterial activity of biocompatible tantalum nanofilm via enhanced local innate immunity," Acta Biomaterialia, vol. 89, pp. 403-418, 2019.

[45] L. Burton, D. Paget, N. B. Binder et al., "Orthopedic wear debris mediated inflammatory osteolysis is mediated in part by NALP3 inflammasome activation," Journal of Orthopaedic Research, vol. 31, no. 1, pp. 73-80, 2013.

[46] E. Jämsen, J. Pajarinen, V.-P. Kouri et al., "Tumor necrosis factor primes and metal particles activate the NLRP3 inflammasome in human primary macrophages," Acta Biomaterialia, vol. 108, pp. 347-357, 2020.

[47] G. W. Manzano, B. P. Fort, G. R. Dubyak, and E. M. Greenfield, "Wear particle-induced priming of the NLRP3 inflammasome depends on adherent pathogen-associated molecular patterns and their cognate Toll-like receptors: an in vitro study," Clinical orthopaedics and related research, vol. 476, no. 12, pp. $2442-$ 2453, 2018.

[48] E. M. Greenfield, M. A. Beidelschies, J. M. Tatro, V. M. Goldberg, and A. G. Hise, "Bacterial pathogen-associated molecular patterns stimulate biological activity of orthopaedic wear particles by activating cognate Toll-like receptors," Journal of Biological Chemistry, vol. 285, no. 42, pp. 32378-32384, 2010.

[49] J. S. Bezbradica, R. C. Coll, and K. Schroder, "Sterile signals generate weaker and delayed macrophage NLRP3 inflammasome responses relative to microbial signals," Cellular \& Molecular Immunology, vol. 14, no. 1, pp. 118-126, 2017.

[50] P. Khanna, C. Ong, B. H. Bay, and G. H. Baeg, "Nanotoxicity: an interplay of oxidative stress, inflammation and cell death," Nanomaterials, vol. 5, no. 3, pp. 1163-1180, 2015.

[51] L. Wang, X. Hu, X. Ma et al., "Promotion of osteointegration under diabetic conditions by tantalum coating-based surface modification on 3-dimensional printed porous titanium implants," Colloids and Surfaces B: Biointerfaces, vol. 148, pp. 440-452, 2016.

[52] C.-Q. Luo, L. Xing, P.-F. Cui et al., "Curcumin-coordinated nanoparticles with improved stability for reactive oxygen species-responsive drug delivery in lung cancer therapy," International Journal of Nanomedicine, vol. Volume 12, pp. 855-869, 2017.
[53] K.-I. Lee, C.-C. Su, K.-M. Fang, C.-C. Wu, C.-T. Wu, and Y.-W. Chen, "Ultrafine silicon dioxide nanoparticles cause lung epithelial cells apoptosis via oxidative stress-activated PI3K/Akt-mediated mitochondria-and endoplasmic reticulum stress-dependent signaling pathways," Scientific Reports, vol. 10, no. 1, pp. 1-13, 2020.

[54] T. Morishige, Y. Yoshioka, A. Tanabe et al., “Titanium dioxide induces different levels of IL- $1 \beta$ production dependent on its particle characteristics through caspase- 1 activation mediated by reactive oxygen species and cathepsin B," Biochemical and Biophysical Research Communications, vol. 392, no. 2, pp. 160-165, 2010.

[55] T. Adachi, K. Takahara, J. Taneo, Y. Uchiyama, and K. Inaba, "Particle Size of Latex Beads Dictates IL- $1 \beta$ Production Mechanism," PloS one, vol. 8, no. 7, p. e68499, 2013.

[56] H. Yao, Y. Zhang, L. Liu et al., "Inhibition of lanthanide nanocrystal-induced inflammasome activation in macrophages by a surface coating peptide through abrogation of ROS production and TRPM2-mediated $\mathrm{Ca}^{2+}$ influx," Biomaterials, vol. 108, pp. 143-156, 2016.

[57] O. Lunov, T. Syrovets, C. Loos et al., "Amino-functionalized polystyrene nanoparticles activate the NLRP3 inflammasome in human macrophages," ACS Nano, vol. 5, no. 12, pp. $9648-$ 9657, 2011.

[58] X. Pan, X. Wu, D. Yan, C. Peng, C. Rao, and H. Yan, “Acrylamide-induced oxidative stress and inflammatory response are alleviated by $\mathrm{N}$-acetylcysteine in PC12 cells: involvement of the crosstalk between Nrf2 and NF- $\kappa \mathrm{B}$ pathways regulated by MAPKs," Toxicology Letters, vol. 288, pp. 55-64, 2018.

[59] S. S. Karuppagounder, L. Alin, Y. Chen et al., "N-Acetylcysteine targets 5 lipoxygenase-derived, toxic lipids and can synergize with prostaglandin E2to inhibit ferroptosis and improve outcomes following hemorrhagic stroke in mice," Ann Neurol, vol. 84, no. 6, pp. 854-872, 2018.

[60] S. Kim, J. Jang, H. Kim, H. Choi, K. Lee, and I.-H. Choi, "The effects of silica nanoparticles in macrophage cells," Immune network, vol. 12, no. 6, pp. 296-300, 2012. 